\title{
500 anos de relações entre Brasil e Portugal
}

\author{
JOSÉ FLÁVIO SOMBRA SARAIVA
}

A Universidade de Brasília abrigou, nos dias 27 e 28 de abril, evento relevante para as sociedades brasileira e portuguesa. Organizado pelos Professores Amado Luiz Cervo e José Flávio Sombra Saraiva, o Simpósio Internacional "500 Anos de Relações entre Portugal e Brasil” ambientou-se no contexto das comemorações do V Centenário do Brasil. Com apoio organizacional do Instituto Brasileiro de Relações Internacionais (IBRI) e institucional do Instituto Camões e da Fundação Alexandre de Gusmão, o simpósio reuniu portugueses e brasileiros especialistas no estudo das relações internacionais.

Com grande adesão de público, o encontro foi presidido com um objetivo estratégico explícito: superar a falta de comunicação entre as duas academias. Como que de costas uns para os outros, portugueses e brasileiros que analisam a cena internacional continuam abordando a inserção internacional de seus países sem considerar os conhecimentos gerados por cada um dos países na área e sem explorar as possibilidades de uma comunicação mais estreita entre os pares dos dois lados do Atlântico. Algumas dificuldades históricas nas relações bilaterais explicam em parte esse distanciamento. O mal-estar gerado pelo colonialismo tardio e o apoio que, a contragosto, a diplomacia brasileira lhe emprestava, criavam dificuldades práticas para a aproximação. Mas também a auto-suficiência acadêmica de ambos os lados contribui, em muito, para o afastamento da convivência intelectual entre ambos.

O resultado mais evidente do simpósio foi, nesse sentido, o de avançar na construção de um novo clima de trabalhos entre os especialistas de forma a encorajar a exploração de temas comuns para a pesquisa e propor a revisão de tantos preconceitos acalentados pela ignorância. Nesse sentido, procurou-se caminhar na linha que permitia certa reaproximação, ainda que lenta, entre os dois lados. $\mathrm{O}$ ambiente internacional no qual esse novo diálogo se estabelece tem algo a contribuir. Desde a retirada de Portugal da África, entre 1974 e 1975, e sua nova estratégia de inserção internacional, animada pela redemocratização e por uma crescente europeização daquele país e pela busca de um novo lugar no mundo, novas condições se apresentaram para que se removessem os obstáculos a uma melhor relação entre Portugal e Brasil.

A década de 1990, no entanto, foi marcadamente frutífera na aproximação entre os dois países. O novo tempo, não mais caracterizado pelo formalismo improdutivo e pela diplomacia dos punhos de renda, é o dos empresários portugueses 
ativos nos processos de privatização das estatais brasileiras e dos investimentos diretos de grupos portugueses no sistema financeiro brasileiro. A força das novas relações Brasil-Portugal reside não apenas nos discursos de sensibilidades, paixões e saudades, mas na relevância dos intercâmbios materiais entre as duas sociedades.

Nesse sentido, o simpósio de Brasília foi um passo decisivo em uma linha de cooperação universitária já em curso. Registrem-se, por exemplo, a presença de especialistas brasileiros nas II Jornadas de Relações Internacionais da Universidade Lusíada, no Porto, em 1999, bem como a grande delegação do Brasil que se deslocou para as III Jornadas, de maio de 2000, para discutir, com seus colegas brasileiros, o tema "Portugal, o Atlântico e o Brasil”. Destaca-se também a realização do Primeiro Encontro Luso-Brasileiro de Relações Internacionais, realizado nos dias 30 e 31 de agosto de 1999, no Convento da Arrábida, sob os auspícios da Comissão dos Descobrimentos Portugueses. Figura ainda o Congresso de Braga, de junho do corrente ano, no qual os capítulos de ciência política e relações internacionais do Congresso Brasil-Portugal ampliam a discussão do Atlântico como um espaço comum de comunicação entre brasileiros, portugueses e africanos.

Em Brasília, o eixo foi o das relações bilaterais. Matéria ainda não tratada com a densidade exposta pelo Simpósio "500 Anos de relações entre Portugal e Brasil”, ela ganhou grande impulso com a qualidade das conferências e o vigor dos debates. Um primeiro quadro, dedicado à herança do passado e às relações bilaterais, foi apresentado por vários estudiosos. Amado Luiz Cervo, da Universidade de Brasília, sublinhou as novas descobertas nas relações bilaterais Brasil-Portugal nos séculos XIX e XX. Traçou uma nova periodização e estabeleceu os temas de longo prazo. Lúcia Maris Bastos P. Neves e Tânia Maria Tavares Bessone, da Universidade Estadual do Rio de Janeiro, expuseram os grandes temas das relações culturais entre os dois países no século XIX e XX. José Medeiros Ferreira, do Instituto de Ciências Políticas de Lisboa, avaliou um momento especial das relações Brasil-Portugal: o contexto do 25 de abril de 1974.

Um segundo quadro de discussões foi proposto: o dos novos desafios para a inserção conjunta do Brasil e de Portugal em um mundo cheio de incertezas e de complexidade que nos cerca. Fernando de Sousa, da Universidade Lusíada do Porto, analisou os passos da inserção periférica de Portugal na Europa, lembrou as vantagens que esse processo trouxe para a modernização portuguesa e observou os riscos criados pela maneira em que o processo ocorreu. Williams Gonçalves, da Universidade Estadual do Rio de Janeiro, discutiu a ambígua posição brasileira na Comunidade dos Países de Língua Portuguesa (CPLP). Paulo Gilberto Vizentini, da Universidade Federal do Rio Grande do Sul, demonstrou como o Brasil procurou, e ainda procura, fazer certo contraponto à presença portuguesa no processo de independência do Timor Leste. José Jobson Arruda, da Universidade de São Paulo, demonstrou como houve uma trajetória amadurecida em Portugal, ao contrário do 
Brasil, na formação de equipes de trabalho governamentais e não-governamentais voltadas para a organização das atividades comemorativas dos descobrimentos.

O terceiro eixo dos debates em Brasília foi o dos estudos comparados e o da imagem mútua. José Tengarrinha e João Medina, da Universidade Clássica de Lisboa; Luiz Adão da Fonseca, da Universidade do Porto; Antônio Dias Farinha, da Universidade de Lisboa; e Rui Rasquilho, do Instituto Camões, abordaram os diferentes momentos em que as relações entre os dois países foram marcadas por imagens distorcidas e desinteligências.

O quarto eixo foi o da nova agenda diplomática bilateral entre Brasil e Portugal, abordada pelo Embaixador de Portugal no Brasil, Francisco Knopfi, que sublinhou a parceria estratégica que vem se estruturando entre os dois países. Os desejos do passado, especialmente a comunhão espiritual que unia brasileiros e portugueses, são agora fortalecidos por um momento rico em intercâmbios e objetivos estratégicos comuns, como a possibilidade de ampliação dos intercâmbios entre o Mercosul e a União Européia. As negociações em favor da área de livrecomércio têm, nos dois lados do Atlântico, árduos defensores nas diplomacias do Brasil e de Portugal.

Last but not least, o simpósio foi coroado com a obra pioneira, escrita por Amado Luiz Cervo e José Calvet de Magalhães, Depois das Caravelas: as relações entre Portugal e Brasil, 1808-2000 (Brasília: EdUnb, 2000) que passa em revista os dois séculos do relacionamento e abre portas para estudos de temas específicos. O novo tratado das relações Brasil-Portugal é parte dos olhares mais atentos entre as duas sociedades.

Maio de 2000 